\title{
"The leading role of pathology in assessing the somatic molecular alterations of cancer: Position Paper of the European Society of Pathology": letter to the Editor
}

\author{
Winand N. M. Dinjens ${ }^{1} \cdot$ Marjolijn J. L. Ligtenberg ${ }^{2,3} \cdot$ Tom van Wezel $^{4} \cdot$ Ed Schuuring $^{5} \cdot$ Hendrikus Jan Dubbink $^{1}$
}

Published online: 6 August 2020

(C) The Author(s) 2020

Keywords Molecular pathology $\cdot$ Molecular diagnostics

To the Editor:

In a recent Virchows Archiv publication, Matias-Guiu et al. [1] indicate the central role for pathology in oncology molecular diagnostics. Motivated by this publication, we would like to make several comments.

First, the authors indicate that molecular results must be interpreted in light of morphology and location of the lesion. However, interpretation of molecular results in relation to tumor genetic concepts and molecular (oncogenic and resistance) pathways is also crucial. This accounts not only for molecular analyses of tissues but also of circulating tumor DNA (ctDNA) from liquid biopsies.

Second, as stated, molecular pathology is different from other laboratory specialties because of the oncological pathology specific situation as the use of routine pathology specimens (FFPE, cytology) composed of a mixture of neoplastic

This article is part of the Topical Collection on Quality in Pathology

Winand N. M. Dinjens

w.dinjens@erasmusmc.nl

1 Department of Pathology, Erasmus MC Cancer Institute, University Medical Center Rotterdam, P.O. Box 2040, 3000

CA Rotterdam, The Netherlands

2 Department of Pathology, Radboud University Medical Center, Nijmegen, The Netherlands

3 Department of Human Genetics, Radboud University Medical Center, Nijmegen, The Netherlands

4 Department of Pathology, Leiden University Medical Center, Leiden, The Netherlands

5 Department of Pathology, University Medical Center Groningen, University of Groningen, Groningen, The Netherlands and normal cells, and from which often only minute amounts of largely degraded nucleic acids can be retrieved. This pathology-specific molecular biological situation was recognized by the Dutch Pathological Society which implemented since 2014 a 2-year educational program to become a Clinical Scientist in Molecular Pathology (CSMP) [2]. Furthermore, the Dutch Pathological Society established the guideline that pathology laboratories performing molecular pathology should have access to a registered CSMP.

Third, we agree that molecular results should be part of state-of-the-art integrated diagnostics. For securing accredited quality and cost-effective diagnostics, regional centralization of molecular pathology will be inescapable. Ideally, pathologists and CSMPs take the lead in this regionalization and do not leave this to hospitals, insurance companies, or governmental bodies. Within such a regionalized situation, it is important that all pathologists within a region have easy access to the molecular pathology laboratory for consultation and education. In addition, regional molecular tumor boards (MTBs), discussing complex molecular results in the context of clinical and pathological data, should be easy accessible (virtual) for all pathologists, CSMPs, and clinicians.

Fourth, the publication is a plea to perform oncological molecular diagnostics within pathology departments. We think indeed that this is crucial for the best patient care. However, solely the plea is not sufficient; this central role in oncology diagnostics has to be deserved by pathology departments. This implies that pathologists need to have broad knowledge of molecular pathology: basic molecular biology including its language and tumor genetic concepts and pathways including targeted treatment resistance mechanisms. In addition, pathologists and CSMPs, in close contact with oncologists, need to keep up with evolving carcinogenesis concepts, implementing new molecular markers, up-to-date molecular technologies, and treatment options. 
As a result of the above, it is clear that the pathologist of the future (and current!) has to be a molecular pathologist. Therefore, we would like to plea for implementation of a substantial part (20-25\%) of pathology resident training programs to molecular pathology. These molecular pathologists, together with CSMPs, will play a crucial role in translating morphological and molecular features of tumors to diagnostic and predictive parameters that facilitate optimal personalized treatment. As a result, we expect that the leading role of the discipline Pathology in assessing somatic alterations in cancer will be broadly recognized and assigned.

Author contributions Winand N.M. Dinjens wrote the manuscript; all other authors made amendments and approved the final version.

\section{Compliance with ethical standards Not applicable}

Conflict of interest The authors declare that they have no conflict of interest.

Open Access This article is licensed under a Creative Commons Attribution 4.0 International License, which permits use, sharing, adaptation, distribution and reproduction in any medium or format, as long as you give appropriate credit to the original author(s) and the source, provide a link to the Creative Commons licence, and indicate if changes were made. The images or other third party material in this article are included in the article's Creative Commons licence, unless indicated otherwise in a credit line to the material. If material is not included in the article's Creative Commons licence and your intended use is not permitted by statutory regulation or exceeds the permitted use, you will need to obtain permission directly from the copyright holder. To view a copy of this licence, visit http://creativecommons.org/licenses/by/4.0/.

\section{References}

1. Matias-Guiu X, Stanta G, Carneiro F, Ryska A, Hoefler G, Moch H, on behalf of the European Society of Pathology (ESP) (2020) The leading role of pathology in assessing the somatic molecular alterations of cancer: position paper of the European Society of Pathology. Virchows Arch 476:491-497

2. Dubbink HJ, Deans ZC, Tops BB, van Kemenade FJ, Koljenović S, van Krieken HJ, Blokx WA, Dinjens WN, Groenen PJ (2014) Next generation diagnostic molecular pathology: critical appraisal of quality assurance in Europe. Mol Oncol 8:830-839

Publisher's note Springer Nature remains neutral with regard to jurisdictional claims in published maps and institutional affiliations. 